\title{
Response Characteristics of Coal-Like Material Subjected to Repeated Hydraulic Fracturing: An Evaluation Based on Real-Time Monitoring of Water Injection Pressure and Roof Stress Distribution
}

\author{
Yongjiang Zhang $\mathbb{D}$, Benqing Yuan, and Xingang Niu \\ Gas Prevention and Control Branch, Chongqing Research Institute, China Coal Technology Engineering Group, \\ State Key Laboratory of the Gas Disaster Detecting, Preventing and Emergency Controlling, Chongqing 400037, China \\ Correspondence should be addressed to Yongjiang Zhang; 25789384@qq.com
}

Received 16 March 2021; Accepted 19 May 2021; Published 28 May 2021

Academic Editor: Feng Du

Copyright (c) 2021 Yongjiang Zhang et al. This is an open access article distributed under the Creative Commons Attribution License, which permits unrestricted use, distribution, and reproduction in any medium, provided the original work is properly cited.

\begin{abstract}
Conventional hydraulic fracturing has several disadvantages, including a short effective extraction time and low fracture conductivity during long-term extraction. Aiming at overcoming these shortcomings, a similar simulation test of repeated hydraulic fracturing was conducted in this study, and the evolutionary rules regarding the injection water pressure and stress distribution of the coal seam roof during this repeated hydraulic fracturing were revealed. The research results show that after multiple hydraulic fracturing, the number of cracks in the coal seam and the range of fracturing influence have increased significantly. As the number of fracturing increases, the initial pressure required for cracking decreases. The highest water injection pressure of the first fracturing was $2.8 \mathrm{MPa}$, while the highest water injection pressures of the second and third fracturing were $2.7 \mathrm{MPa}$ and $2.4 \mathrm{MPa}$, respectively. As the number of fracturing increases, the area of increased stress will continue to expand. After the first fracturing, the impact radius of fracturing is $100 \mathrm{~cm}$. After the second fracturing, the radius of influence of fracturing expanded to $150 \mathrm{~cm}$. When the third fracturing was over, the radius of influence of the fracturing expanded to approximately $250 \mathrm{~cm}$. It can be seen that, compared with conventional hydraulic fracturing, repeated hydraulic fracturing shows better fracturing effect. The research results can be used as a basis for repeated hydraulic fracturing field tests to increase coal seam permeability.
\end{abstract}

\section{Introduction}

As coal mines of deep areas are mined, the characteristics of coal seams, i.e., their low permeability, great gas extraction difficulty, and low extraction efficiency, are becoming significant $[1-5]$. Underground hydraulic fracturing technology for coal mines, as an important measure for controlling gas disasters, can be used to open, propagate, and extend cracks in coal seams, which fully relieve the pressure on the coal mass and increase the permeability of the coal seams. Moreover, this improves the gas extraction rate and effectively prevents dynamic disasters such as coal and gas outbursts. Therefore, it has been widely studied and applied in recent years [6-10].
At present, scholars have studied the mechanism of hydraulic fracturing to increase permeability [11-15], the development of hydraulic fracturing technology and equipment [16-20], and on-site testing and evaluation [21-25]. And it is concluded that hydraulic fracturing can significantly improve the permeability of coal seams, which is an effective technology for controlling gas disasters $[26,27]$. However, at present, the qualitative research on hydraulic fracturing is in the majority, and the theoretical research is not deep enough. After the implementation of hydraulic fracturing, the initiation and propagation of fracture are affected by many factors, such as coal seam gas pressure, physical, and mechanical properties of surrounding rock mass and stress distribution, which makes it 
difficult to be studied quantitatively. Moreover, most research studies focus on single hydraulic fracturing, and the effect of single hydraulic fracturing is often due to insufficient fracture propagation and uneven extension, resulting in poor permeability enhancement. The quantitative characterization of repetitive hydraulic fracturing for fracture propagation and coal seam increase requires further research.

Therefore, based on a similar simulation test, this study compared and analyzed the water injection pressure, flow, crack initiation and propagation direction, and change law for the range of the roof stress of the coal seam during fracturing. The purpose was to explore the effects of repeated hydraulic fracturing on the fracturing range of coal seams compared with conventional hydraulic fracturing. It is expected to provide a basis for increasing the permeability of coal seams so as to achieve the purpose of extracting coal seam gas efficiently and at low cost.

\section{Experimental System and Procedures}

2.1. Experimental System. The similar simulation test system for the hydraulic fracturing primarily consisted of a test model box, an in situ stress loading system, a data acquisition system for the in situ stress, a water pressure acquisition system, a pumping source device, and other auxiliary devices. A schematic diagram for the connection of the similar simulation test system for hydraulic fracturing is shown in Figure 1.

The test components are described as follows.

2.1.1. Test Model. The square test model box was welded with $10 \mathrm{~mm}$ thick Q345 steel plates on the bottom and four sides. The dimensions of the internal space (length $\times$ width $\times$ height) were $500 \mathrm{~mm} \times 500 \mathrm{~mm} \times 600 \mathrm{~mm}$.

2.1.2. Stress Loading System. The in situ stress loading system in this test consisted of a hydraulic jack with a measurement range of $0-10 \mathrm{MPa}$ and a counterforce frame. The maximum jacking force of the hydraulic cylinder was $10 \mathrm{t}$. The counterforce frame was supported by four cylindrical screws with diameters of $300 \mathrm{~mm}$, which could bear $2 \mathrm{MPa}$ of force with no obvious deformation.

2.1.3. Data Acquisiltion System. In this test, the fracturing hole was regarded as the center, and miniature stress cells were arranged in the roof of the coal seam in the model at regular intervals. The USB cables of these stress cells were connected to a YE2539 high-speed static strain gauge. Data were acquired during the water injection process of hydraulic fracturing, to observe the change trend of the stress in the roof and floor of the coal seam during the entire process. The arrangement of miniature stress cells is shown in Figure 2. By centering the fracturing hole, the first miniature earth stress cell (number C001) was $5 \mathrm{~cm}$ away from the fracturing hole. The fracturing cells were arranged every $5 \mathrm{~cm}$, which made a total of 6 miniature stress cells. The stress cells used in the test were resistance strain models with a measuring range of $0-6 \mathrm{MPa}$, and their built-in circuits adopted the full-bridge connection. The stress surfaces of resistance strain-type earth stress cells must be polished before use to avoid introducing too many impurities. The resistance test was conducted using a multimeter. This multimeter was only used when the resistance between any two wires had a reasonable value. Figure 3 shows pictures of the YE2539 high-speed static strain gauge and the resistance of the miniature stress cell being measured.

2.1.4. Water Pressure Acquisition System. To monitor and record changes in the water injection pressure during the hydraulic fracturing process effectively, this test utilized an automatic acquisition instrument for water pressure data to record the water pressure automatically in real time in the test. A picture of this automatic acquisition instrument for water pressure data is displayed in Figure 4.

2.1.5. Water Pump. The JZ1.6-4.0/20 plunger metering pump used in this test has a maximum rated flow of $4.0 \mathrm{~L} / \mathrm{h}$ and can provide a maximum water pressure of $20 \mathrm{MPa}$. Its motor has a working power of $0.37 \mathrm{~kW}$, and the diameters of the inlet and outlet are both $4 \mathrm{~mm}$. Moreover, it has a suitable medium temperature of not higher than $200^{\circ} \mathrm{C}$ and a stabilized flow viscosity of $\pm 1 \%$. Flange connections were adopted to connect the inlet and outlet and could be adjusted when the pump was running or stopped.

2.2. Sample Preparation. This test model included three layers (a roof stratum, coal seam, and floor stratum), with a laying thickness of $200 \mathrm{~mm}$ for each layer. Materials were selected based on the characteristics of the coal seam, the roof, and floor strata. Materials similar to the coal seam, river sand, and coal powder were used as aggregates, and cement and gypsum were used as cementing materials. The roof and floor were prepared using river sand (aggregate) and cement (cementing material). The ratio of the similar materials used for the roof stratum was as follows: river sand:cement: gypsum : coal powder $=5: 0.5: 0.5: 0$, while that for floor stratum was as follows: river sand:cement:gypsum:coal powder $=5: 0.3: 0.7: 0$. In addition, the ratio of the similar materials used for the coal seam was as follows: river sand: cement : gypsum : coal powder $=6: 0.3: 0.7: 1$. Before laying the similar simulation materials, various similar materials were weighed using a platform scale in accordance with the above ratios and stirred uniformly. Based on the test design, these materials were laid according to the order of the floor, coal seam, and roof, with each layer laid in a single operation. Furthermore, after being laid, each layer was dehydrated and maintained for a period before the next layer was laid, to prevent the mixing or separating of materials on each layer. After all of the layers were laid and solidified, the counterforce frame and jack were installed to perform stress loading on the model. The construction process is shown in Figure 5. 


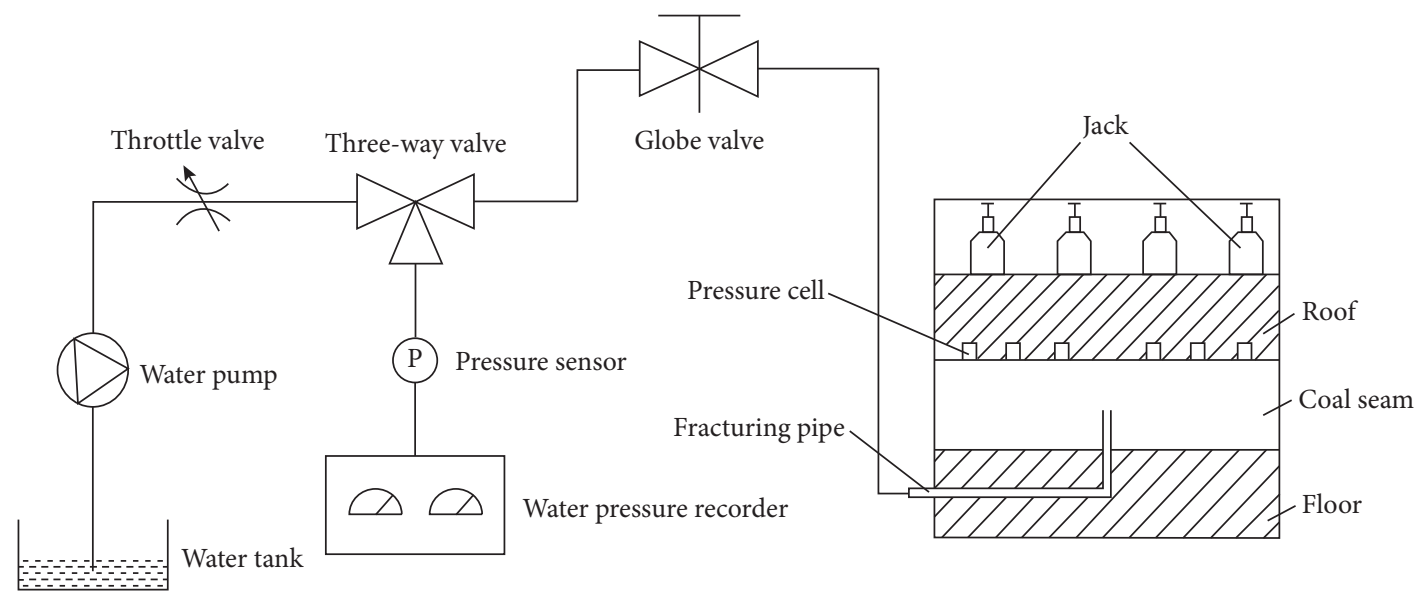

FIgURE 1: Experimental system for hydraulic fracturing.
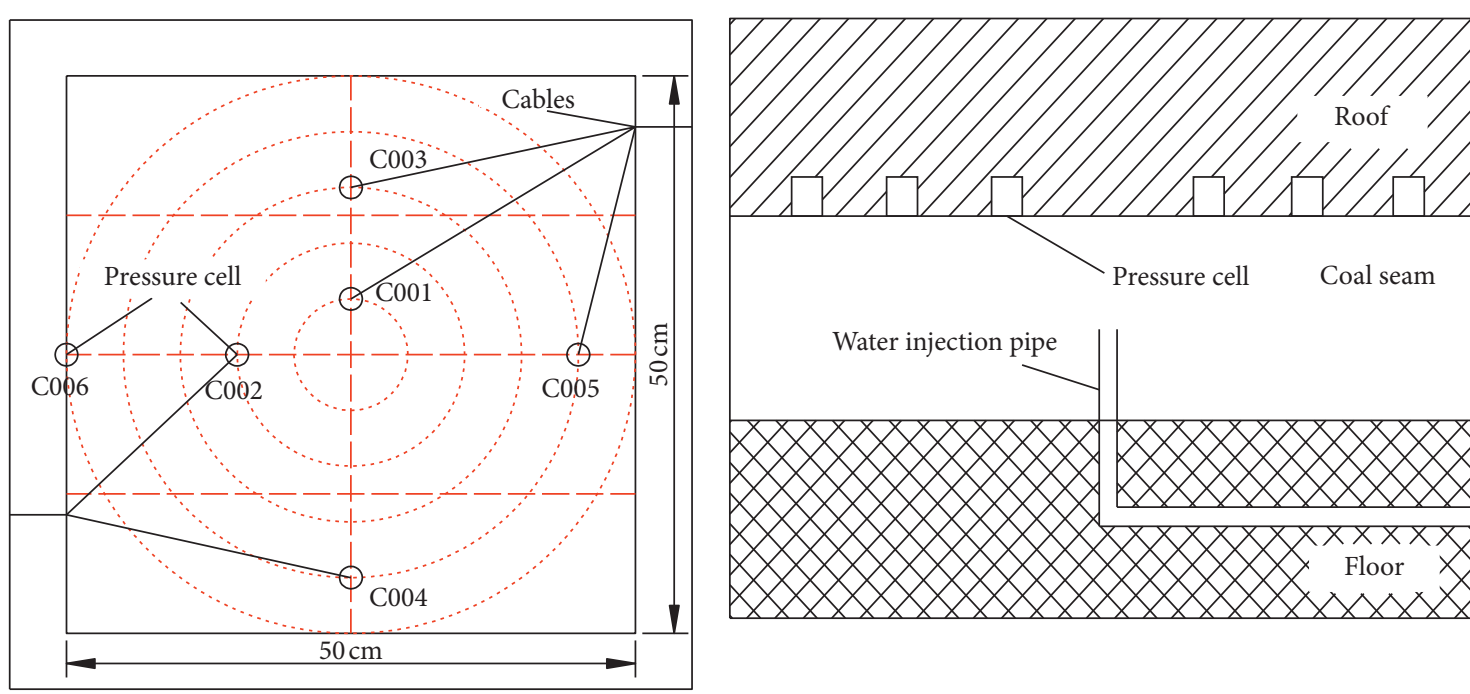

Figure 2: Arrangement of pressure cells.

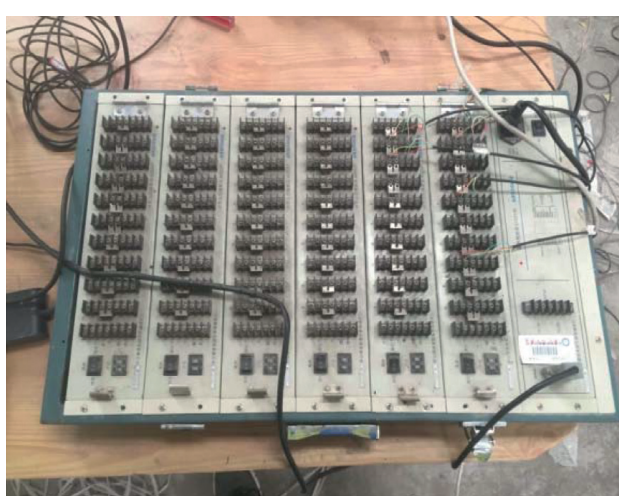

(a)

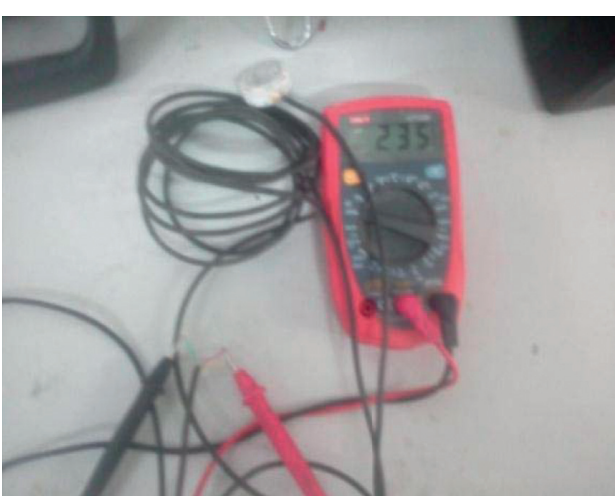

(b)

Figure 3: Pictures of (a) YE2539 high-speed static strain gauge and (b) pressure cell. 


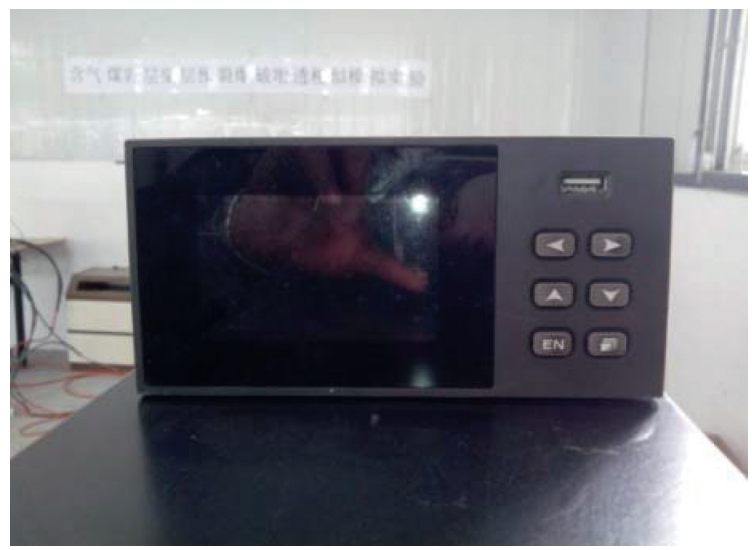

Figure 4: Automatic acquisition instrument for water pressure data.

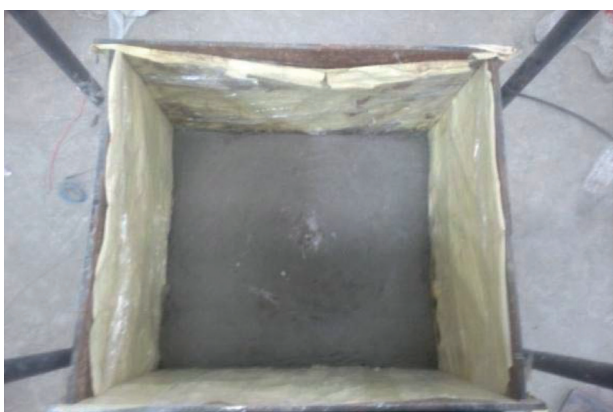

(a)

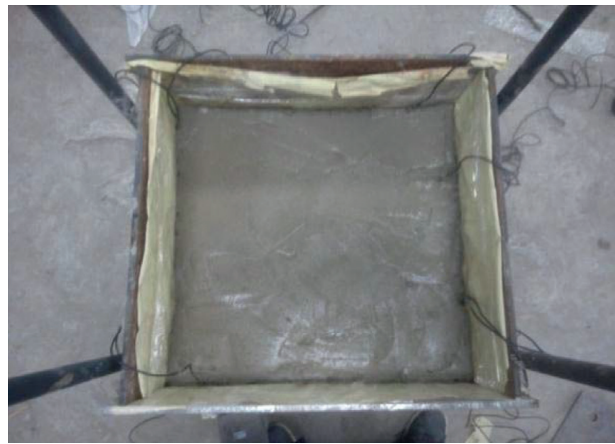

(c)

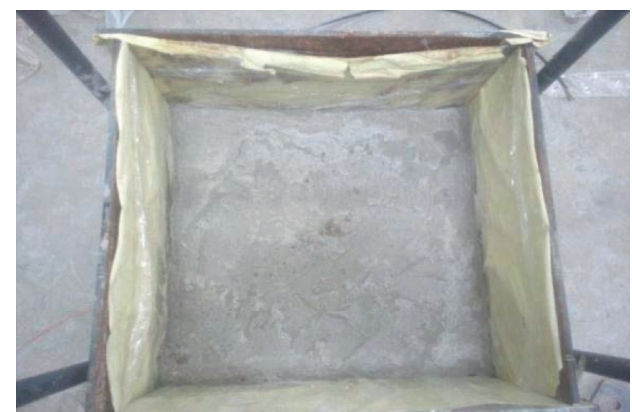

(b)

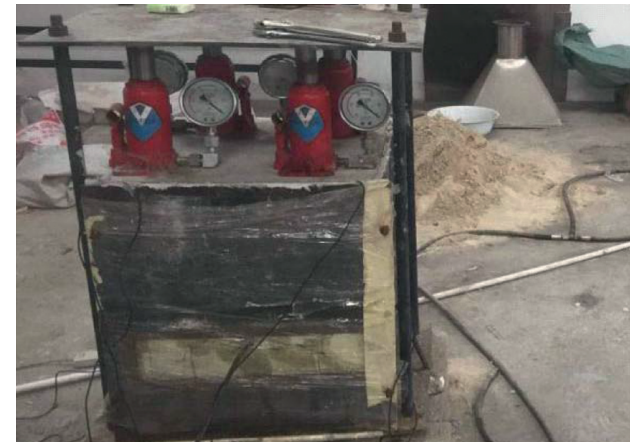

(d)

Figure 5: Construction process for similar model. (a) Construction of floor. (b) Construction of coal seam. (c) Construction of roof. (d) The whole model.

2.3. Experimental Procedures. All of the experimental procedures can be described as follows:

(i) The test devices, including the water pump, high-speed static strain gauge, and automatic acquisition instrument for water pressure, were debugged to ensure the normal operation of each device. According to Figure 1, each test device and high-pressure pipeline was connected, and the connections and seals of the water pump, pipelines, and valves were checked to ensure that the test system was well connected.

(ii) The water hose of the water pump was filled with water to prevent idling of the water pump. The water pressure data and stress data were read by turning on the automatic acquisition instrument for the water pressure and the high-speed static strain gauge, respectively. The water pump was turned on to conduct the hydraulic fracturing test.

(iii) The overflow valve on the water pump was slowly adjusted to control the water injection flow. Moreover, the test tank and surface of the model were observed until cracks appeared on the surface of the model and high-pressure water overflowed from cracks and the four sides of the tank. After injecting water for a period of time, the overflow valve was opened to reduce the water pressure of the system rapidly. After the water pressure had dropped to zero, the water pump was turned off. 
(iv) After $3 \mathrm{~d}$ and $5 \mathrm{~d}$, steps 1-3 were repeated for the second and third fracturing tests, respectively.

\section{Results and Discussion}

3.1. Variations in Water Injection Pressure during Hydraulic Fracturing. Figure 6 shows the variations in the water injection pressure during each hydraulic fracturing process. It can be seen from the figure that the entire fracturing process can be divided into the water pressure accumulation stage, crack initiation stage, and crack propagation stage in accordance with the water pressure change laws. The results of the specific analyses are presented as follows:

Water pressure accumulation stage: after starting the water injection, the injected high-pressure water gradually wets the simulated coal seam, and the initial cracks of the coal seam are full of water. When water injection continues after the pores are filled with water, the water in the pores gradually produces internal water pressure and compressive stress on the pore walls and surrounding cracks. As a large quantity of water is constantly injected, the internal water pressure in the pores continues to increase. During this process, the water pressure in the early stage changes slightly, while that in the late stage increases.

Crack initiation stage: after the water pressure reaches a certain value, the water injection pressure rapidly increases to the peak value. At this time, the tensile stress produced by the water pressure on the weak surfaces of cracks is larger than the tensile strength of the simulated coal seam. Thus, the tips of the cracks begin to crack, and the crack space increases. Moreover, the potential energy of the water changes into kinetic energy, and the water injection pressure decreases slightly. At this stage, the water pressure first rapidly increases to the peak value and then reduces slightly.

Crack propagation stage: when the crack space is again filled with high-pressure water, the kinetic energy of the water is transformed into potential energy, and the water pressure increases. Thus, the cracks are constantly being extended under the effects of the highpressure water until the high-pressure water seeps from the surface cracks of the model or the four sides of the tank. At this stage, the water pressure is experiencing a reciprocating oscillation process with constant increases and decreases, and the water pressure in the late stage is slightly reduces.

As shown in Figure 6, it was also found that during repeated fracturing, with the constant performance of fracturing, the required cracking initiation pressure continually decreased. The peak water injection pressure in the first fracturing was $2.8 \mathrm{MPa}$, while that in the second and third fracturing processes was $2.7 \mathrm{MPa}$ and $2.4 \mathrm{MPa}$, respectively. This was mainly because the repeated fracturing of the coal seam resulted in its fatigue damage. After each fracturing, the fracturing degree of the coal seam gradually increased. Thus, the required initiation pressure continually became lower. In addition, with constant fracturing, the time required to accumulate water pressure to fracture the coal seam increased. Meanwhile, continually increasing amounts of water were needed to fill the cracks in the coal seam. The time required to reach the peak the first time was $723.91 \mathrm{~s}$, while that for the second time was $1086.21 \mathrm{~s}$, which was 1.5 times greater. Furthermore, the time needed to reach the peak the third time was $1517.63 \mathrm{~s}$, which was 2.1 times that of the first time. This was because by constantly fracturing the coal seam, the cracks in the coal seam increased in number and total volume. Thus, the amount of water needed to fill these cracks also increased.

3.2. Variation in Stress in Roof of Coal Seam. Figure 7 shows cloud pictures of the roof stress of the coal seam after injecting water for $200,800,1,000$, and 2,000 s during the first hydraulic fracturing. The roof stress accumulation and transfer of the coal seam during the entire fracturing process can be seen in the figure. In the beginning of the fracturing, because the coal seam was in the water pressure accumulation stage, the roof is slightly affected by the water injection, and only the stress around the water injection hole increases. As the fracturing continues, the stress in the area around the water injection hole rapidly increases, thus forming a stress concentration area. At this time, the water injection pressure reaches the peak, and cracks begin to form in the coal seam. Then, the stress in the area near the water injection hole starts decreasing, mainly because after the initiation and propagation of cracks in the coal seam, the crack space increases and the potential energy of the water in the cracks changes into kinetic energy. The water injection pressure also decreases. With the gradual propagation of the fractured cracks to the surrounding area, the stress concentration area is transferred to the surrounding area, and stress concentration degree continually increases. This is because the pressure in the coal seam around the water injection hole is relieved, and the stress is transferred to the deep area of the coal seam.

In conclusion, the roof stress change is consistent with the change in water injection pressure. The area around the water injection hole is the first to be affected by constant water injection, and the stress gradually rises. When the stress reaches a certain value, the coal mass is fractured, which relieves the pressure and transfers the stress to the surrounding areas. Moreover, cracks propagate to the surrounding areas with the stress transfer. After fracturing, the pressure-relief area and stress concentration area form separately.

Figure 8 displays comparisons of the roof stress distributions of the coal seam during each hydraulic fracturing process. As shown in the figure, when the fracturing is repeated, the area with the increased stress constantly expands, indicating that cracks in the coal seam of the model extend to a larger range deep in the coal mass. The range of influence of the hydraulic fracturing gradually increases with repeated fracturing. After the first fracturing ended, obvious stress changes were only detected by miniature stress cells $\mathrm{C} 001$ and C002. In other words, the range of influence of the 


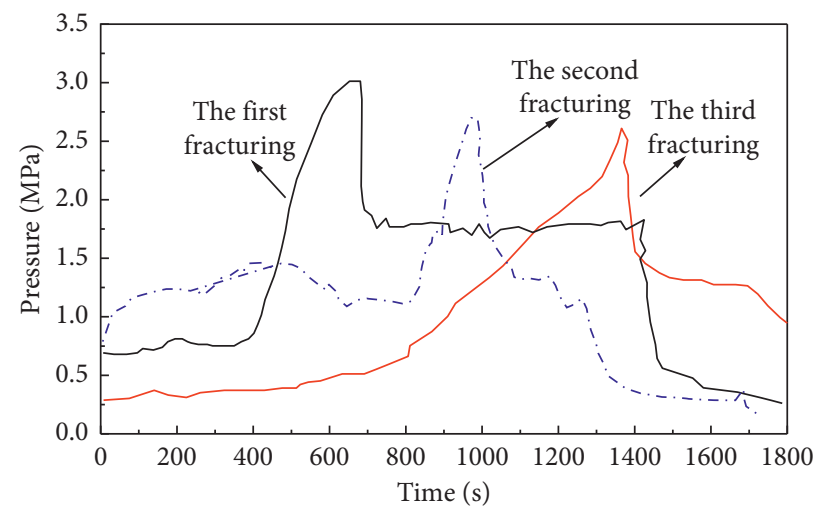

Figure 6: Variations in water injection pressure during each hydraulic fracturing.

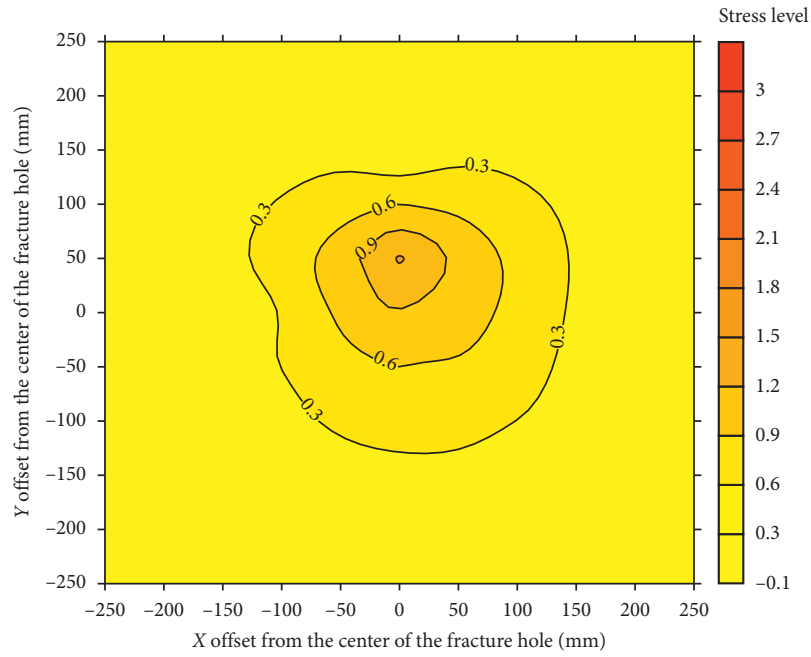

(a)

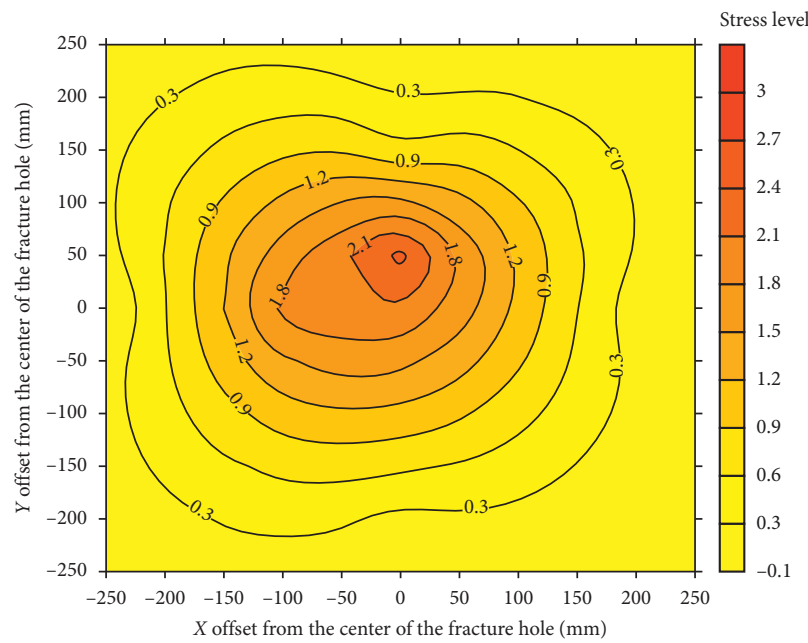

(c)

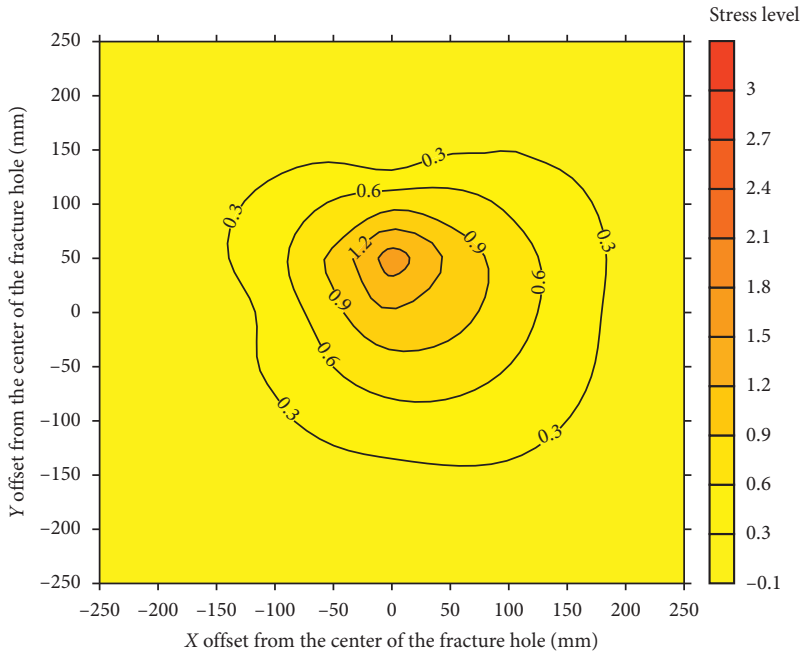

(b)

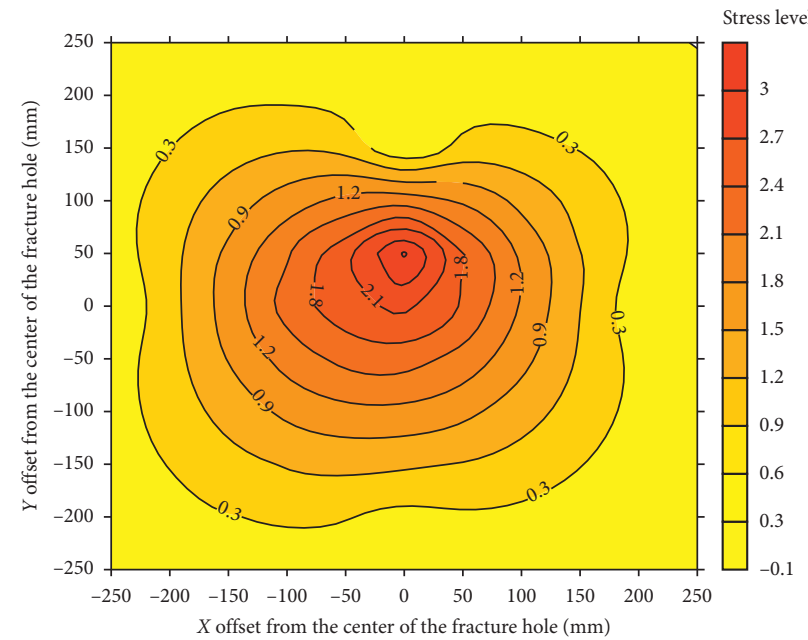

(d)

Figure 7: Cloud pictures of roof stress of coal seam for the first time fracturing: (a) $t=200 \mathrm{~s}$; (b) $t=800 \mathrm{~s}$; (c) $t=1000 \mathrm{~s}$; (d) $t=2000 \mathrm{~s}$.

fracturing was the area affected by the water injection, centered on the water injection hole and showing a radius of $100 \mathrm{~cm}$. After the second fracturing, obvious changes in stress were detected by $\mathrm{C} 001, \mathrm{C} 002$, and $\mathrm{C} 003$, and radius of influence of the fracturing was extended to $150 \mathrm{~cm}$. When the third fracturing ended, C001, C002, C003, C004, and 


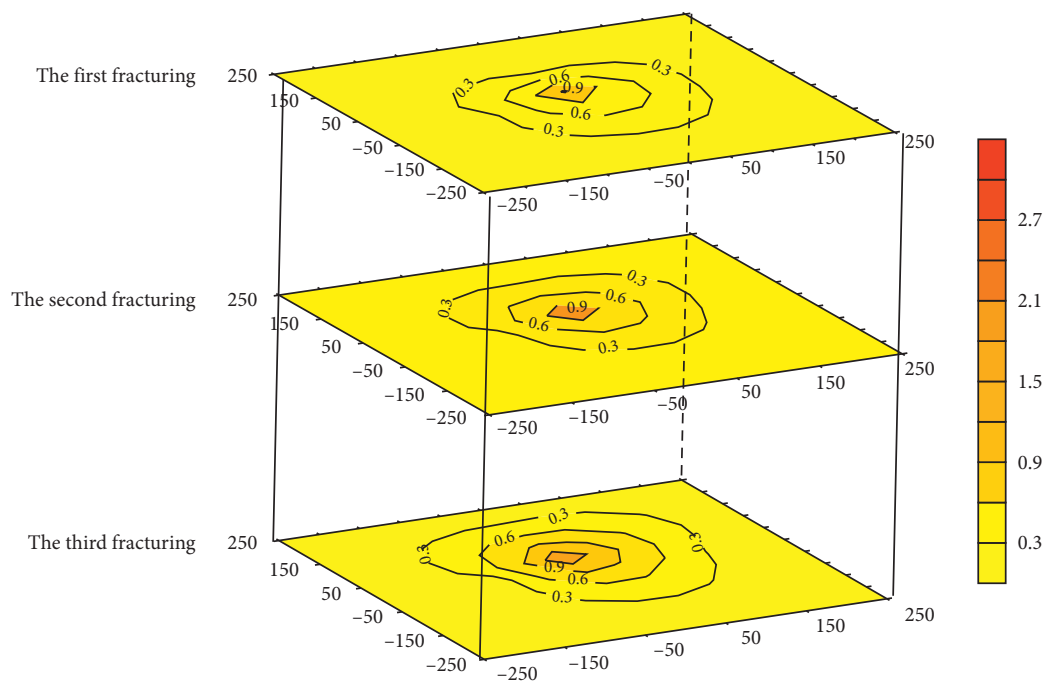

(a)

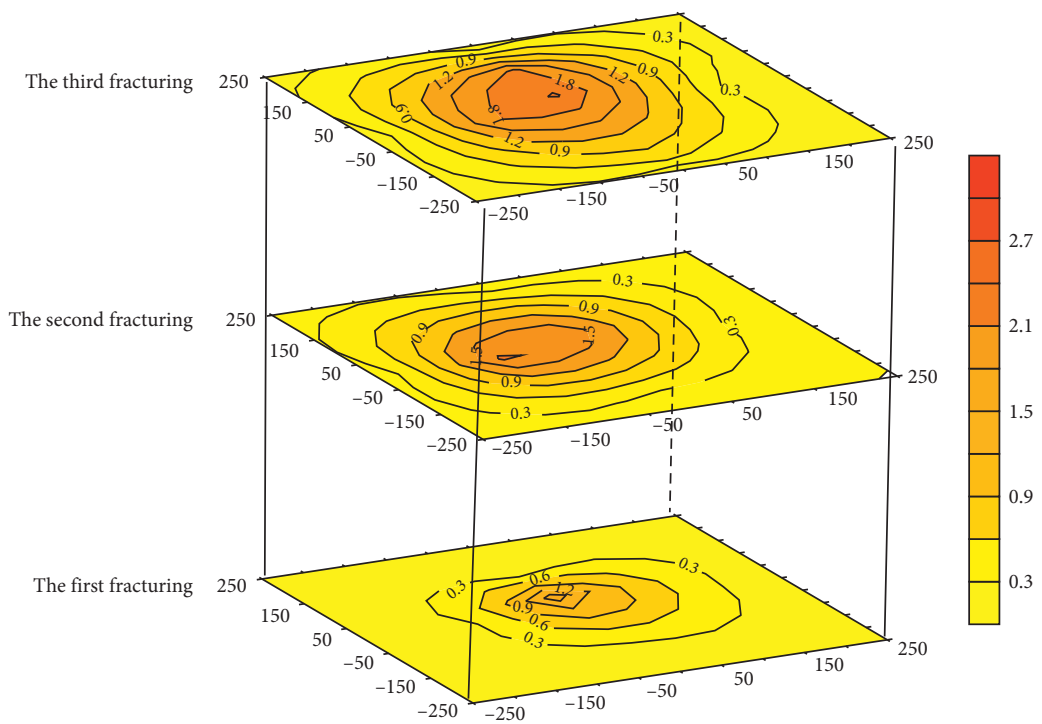

(b)

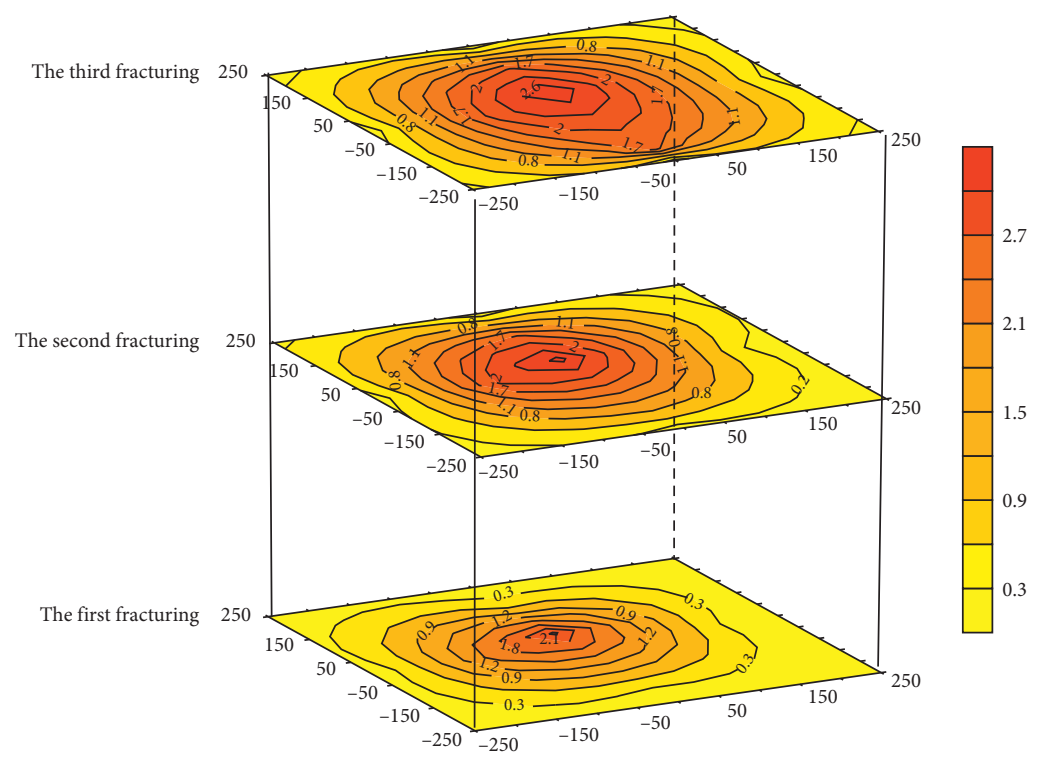

(c)

Figure 8: Continued. 


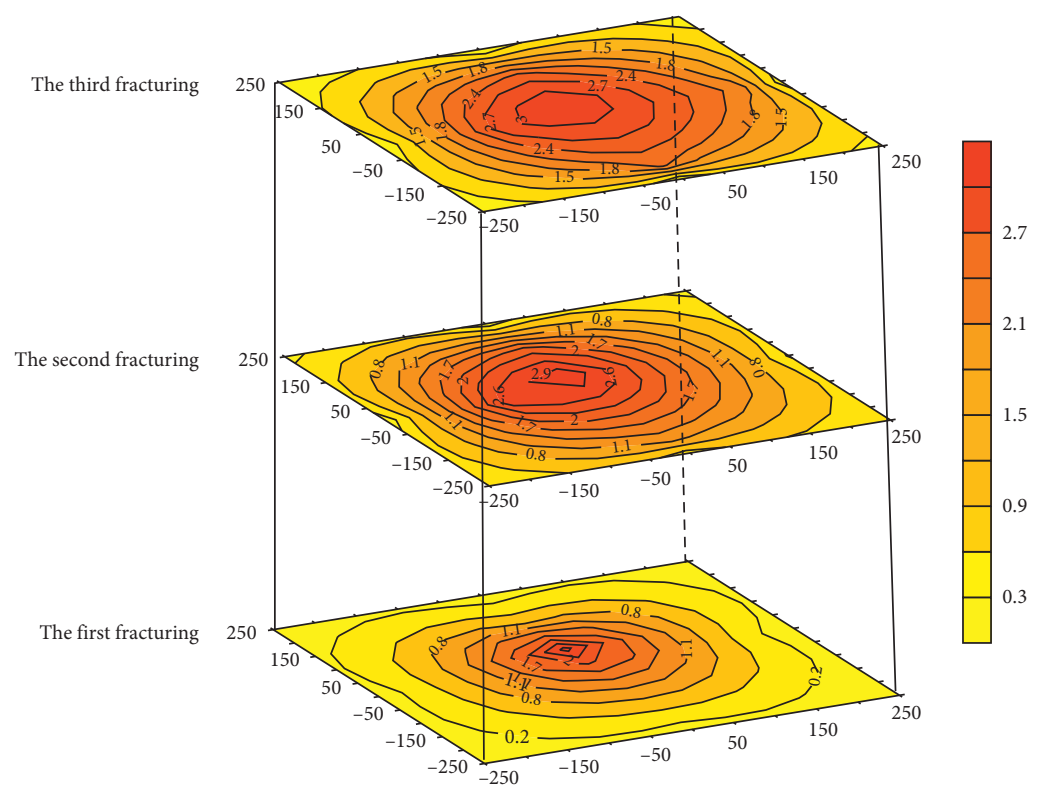

(d)

Figure 8: Comparisons of roof stress distributions of coal seam during each hydraulic fracturing: (a) $t=200 \mathrm{~s}$; (b) $t=800 \mathrm{~s}$; (c) $t=1000 \mathrm{~s}$; (d) $t=2000 \mathrm{~s}$ (the abscissa in the figure represents the offset in the $X$ direction from the fracturing hole, and the ordinate represents the offset in the $Y$ direction from the fracturing hole, and the field value refers to stress level).

C005 showed obvious changes in their readings, and the radius of influence of the fracturing was enlarged to approximately $250 \mathrm{~cm}$. Therefore, the goal of increasing production and efficiency can be achieved by performing repeated fracturing, which extends the crack propagation range of the coal seam and enlarges the area influenced by fracturing.

\section{Conclusions}

In this paper, a similar simulation test of repeated hydraulic fracturing was conducted, and the evolutionary rules regarding the injection water pressure and stress distribution of the coal seam roof during this repeated hydraulic fracturing were revealed. The primary conclusions were displayed as follows:

(1) Based on the change law of the water injection pressure in the similar simulation test, the entire fracturing process could be divided into the water pressure accumulation stage, crack initiation stage, and crack propagation stage. After performing repeated fracturing, the water injection pressure required for fracturing the coal seam decreased.

(2) In the process of repeated hydraulic fracturing, as the number of fracturing continues to increase, the required initial pressure for cracking continues to decrease. The highest water injection pressure of the first fracturing was $2.8 \mathrm{MPa}$, while the highest water injection pressures of the second and third fracturing were $2.7 \mathrm{MPa}$ and $2.4 \mathrm{MPa}$, respectively.

(3) Under constant fracturing, as the number of fracturing continues to increase, the time required for coal seam rupture increases. At the same time, an ever-increasing amount of water is needed to fill the cracks in the coal seam. The time required to reach the peak value for the first time is $723.91 \mathrm{~s}$ and the second time to reach is $1086.21 \mathrm{~s}$, which is 1.5 times the maximum, and the time required to reach the peak value for the third time is $1517.63 \mathrm{~s}$, which is 2.1 times that of the first time.

(4) The roof stress change is consistent with the change in water injection pressure. The area around the water injection hole is the first to be affected by constant water injection, and the stress gradually rises. When the stress reaches a certain value, the coal mass is fractured, which relieves the pressure and transfers the stress to the surrounding areas. Moreover, cracks propagate to the surrounding areas with the stress transfer. After fracturing, the pressure-relief area and stress concentration area form separately.

(5) When fracturing is repeated, the area where the stress increases continues to expand. After the first fracturing, the fracturing influence radius is $100 \mathrm{~cm}$. After the second fracturing, the influence radius of fracturing expanded to $150 \mathrm{~cm}$. When the third fracturing ended, the radius of influence of the fracturing expanded to approximately $250 \mathrm{~cm}$.

It can be concluded that repeated hydraulic fracturing can expand the fracture expansion range of the coal seam and increase the range of fracturing influence. It is expected to provide a basis for increasing the permeability of coal seams so as to achieve the purpose of extracting coal seam gas efficiently and at low cost. 


\section{Data Availability}

The data used to support this study are included within the article.

\section{Conflicts of Interest}

The authors declare that they have no conflicts of interest.

\section{Acknowledgments}

This work was supported by the National Key Research and Development Program of China (2017YFC0804206); General Project of Chongqing Research Institute of China Coal Industry Group Co., Ltd. (2019YBXM31); and General Project of Chongqing Research Institute of China Coal Industry Group Co., Ltd. (2020YBXM22), which are gratefully acknowledged.

\section{References}

[1] Q. Zou, H. Liu, Z. Cheng, T. Zhang, and B. Lin, "Effect of slot inclination angle and borehole-slot ratio on mechanical property of pre-cracked coal: implications for ECBM recovery using hydraulic slotting," Natural Resources Research, vol. 29, no. 3, pp. 1705-1729, 2020.

[2] Y. Liang, J. Dai, Q. Zou, L. Li, and Y. Luo, "Ignition mechanism of gas in goaf induced by the caving and friction of sandstone roof containing pyrite," Process Safety and Environmental Protection, vol. 124, pp. 84-96, 2019.

[3] B. Lin, Q. Zou, Y. Liang, J. Xie, and H. Yang, "Response characteristics of coal subjected to coupling static and waterjet impact loads," International Journal of Rock Mechanics and Mining Sciences, vol. 103, pp. 155-167, 2018.

[4] F. Wu, B. Chen, Q. Zou et al., "Range estimation of horizontal stress of deep rock based on Mohr-Coulomb criterion," Results in Physics, vol. 12, pp. 2107-2111, 2019.

[5] Q. Zou, H. Liu, Y. Zhang, Q. Li, J. Fu, and Q. Hu, "Rationality evaluation of production deployment of outburst-prone coal mines: a case study of nantong coal mine in Chongqing, China," Safety Science, vol. 122, Article ID 104515, 2020.

[6] T. Guo, F. Gong, L. Shen, Z. Qu, N. Qi, and T. Wang, "Multifractured stimulation technique of hydraulic fracturing assisted by radial slim holes," Journal of Petroleum Science and Engineering, vol. 174, pp. 572-583, 2019.

[7] Z. He and B. Duan, "Significance of the dynamic stress perturbations induced by hydraulic fracturing," Journal of Petroleum Science and Engineering, vol. 174, pp. 169-176, 2019.

[8] N. M. Rayudu, X. Tang, and G. Singh, "Simulating three dimensional hydraulic fracture propagation using displacement correlation method," Tunnelling and Underground Space Technology, vol. 85, pp. 84-91, 2019.

[9] M. Vishkai and I. Gates, "On multistage hydraulic fracturing in tight gas reservoirs: montney Formation, Alberta, Canada," Journal of Petroleum Science and Engineering, vol. 174, pp. 1127-1141, 2019.

[10] Q. Zou, B. Lin, C. Zheng et al., "Novel integrated techniques of drilling-slotting-separation-sealing for enhanced coal bed methane recovery in underground coal mines," Journal of Natural Gas Science and Engineering, vol. 26, pp. 960-973, 2015.
[11] X. Li, B. Lin, C. Zhai, Q. Li, and G. Ni, "The mechanism of breaking coal and rock by pulsating pressure wave in single low permeability seam," Journal of China Coal Society, vol. 38, no. 6, pp. 918-923, 2013.

[12] V. Roche, M. van Der Baan, and G. Preisig, "A study of 3D modeling of hydraulic fracturing and stress perturbations during fluid injection," Journal of Petroleum Science and Engineering, vol. 170, pp. 829-843, 2018.

[13] Q. Li, B. Lin, C. Zhai, G. Ni, X. Li, and C. Sun, "Experimental study on action characteristic of pulsating parameters in coal seam pulse hydraulic fracturing," Journal of China Coal Society, vol. 38, no. 7, pp. 1185-1190, 2013.

[14] Q. Li, B. Lin, and C. Zhai, "The effect of pulse frequency on the fracture extension during hydraulic fracturing," Journal of Natural Gas Science and Engineering, vol. 21, pp. 296-303, 2014.

[15] G. Ni, B. Lin, C. Zhai, Q. Li, S. Peng, and X. Li, "Kinetic characteristics of coal gas desorption based on the pulsating injection," International Journal of Mining Science and Technology, vol. 24, no. 5, pp. 631-636, 2014.

[16] W. A. M. Wanniarachchi, P. G. Ranjith, J. C. Li, and M. S. A. Perera, "Numerical simulation of foam-based hydraulic fracturing to optimise perforation spacing and to investigate effect of dip angle on hydraulic fracturing," Journal of Petroleum Science and Engineering, vol. 172, pp. 83-96, 2019.

[17] C. Zhai, M. Li, C. Sun, J. Zhang, W. Yang, and Q. Li, "Guidingcontrolling technology of coal seam hydraulic fracturing fractures extension," International Journal of Mining Science and Technology, vol. 22, no. 6, pp. 831-836, 2012.

[18] Y. Xu, C. Zhai, L. Hao et al., "The pressure relief and permeability increase mechanism of crossing-layers directional hydraulic fracturing and its application," Procedia Engineering, vol. 26, pp. 1184-1193, 2011.

[19] C. Zhai, X. Yu, X. Xiang, Q. Li, S. Wu, and J. Xu, "Experimental study of pulsating water pressure propagation in CBM reservoirs during pulse hydraulic fracturing," Journal of Natural Gas Science and Engineering, vol. 25, pp. 15-22, 2015.

[20] S. E. Saberhosseini, R. Keshavarzi, and K. Ahangari, "A fully coupled three-dimensional hydraulic fracture model to investigate the impact of formation rock mechanical properties and operational parameters on hydraulic fracture opening using cohesive elements method," Arabian Journal of Geosciences, vol. 10, no. 7, p. 157, 2017.

[21] Y. Liang, Y. Cheng, Q. Zou, W. Wang, Y. Ma, and Q. Li, "Response characteristics of coal subjected to hydraulic fracturing: an evaluation based on real-time monitoring of borehole strain and acoustic emission," Journal of Natural Gas Science and Engineering, vol. 38, pp. 402-411, 2017.

[22] G. Ni, H. Xie, G. Li, L. Zhuansun, and Y. Niu, "Improving the permeability of coal seam with pulsating hydraulic fracturing technique: a case study in Changping coal mine, China," Process Safety and Environmental Protection, vol. 117, pp. 565-572, 2018.

[23] B.-X. Huang, B. Yu, F. Feng, Z. Li, Y.-Z. Wang, and J.-R. Liu, "Field investigation into directional hydraulic fracturing for hard roof in Tashan Coal Mine," Journal of Coal Science and Engineering (China), vol. 19, no. 2, pp. 153-159, 2013.

[24] Q. Li, B. Lin, and C. Zhai, "A new technique for preventing and controlling coal and gas outburst hazard with pulse hydraulic fracturing: a case study in Yuwu coal mine, China," Natural Hazards, vol. 75, no. 3, pp. 2931-2946, 2015. 
[25] H. Cheng, Y. Qiao, and C. Dong, "Study on hydraulic fractured gas drainage effect based on Hoek - Brown Criterion," Coal Science and Technology, vol. 46, no. 9, pp. 111-116, 2018.

[26] F. Du, K. Wang, X. Zhang, C. Xin, L. Shu, and G. Wang, "Experimental study of coal-gas outburst: insights from coalrock structure, gas pressure and adsorptivity," Natural Resources Research, vol. 29, no. 4, pp. 2481-2493, 2020.

[27] F. Du and K. Wang, "Unstable failure of gas-bearing coal-rock combination bodies: insights from physical experiments and numerical simulations," Process Safety and Environmental Protection, vol. 129, pp. 264-279, 2019. 